\title{
OPTIMASI PENDISTRIBUSIAN BAWANG PUTIH DENGAN MODEL TRANSPORTASI PADA KELOMPOK TANI SEMBALUN HORTI
}

\author{
Marismiati, Cok Agung Surya Danarjaya Wiratama Sumampan \\ Program Studi Diploma IV Akuntansi Keuangan Politeknik Pos Indonesia Bandung \\ marismiati03@gmail.com
}

\begin{abstract}
Kelompok Tani Sembalun Horti is a group of farmer (GAPOKTAN) located in Sembalun, East Lombok. Kelompok Tani Sembalun Horti which produces garlic, has focused on distributing garlic to several regions in Indonesia. The purpose of this research is to optimize distribution costs that must be borne by Kelompok Tani Sembalun Horti because the distribution costs borne so far are very large. Because distribution costs between regions affect distribution costs that must be borne by the company. The research method used is a qualitative method using data analysis model of Miles and Huberman which begins with data collection, data reduction, data presentation and conclusions. Presentation of data using the transportation method which consists of 3 methods, namely the Northwest Corner, Least Cost, and Vogel's Approximation Method resulting in more optimal distribution costs, especially the Vogel's Approximation Method which optimizes distribution costs to decrease by $15.26 \%$ of the costs that must be borne previously .
\end{abstract}

Keywords: distribution costs, cost optimization, transportation methods

\begin{abstract}
Abstrak
Kelompok Tani Sembalun Horti merupakan gabungan kelompok tani (GAPOKTAN) yang berada di Sembalun, Lombok Timur. Kelompok Tani Sembalun Horti sebagai penghasil bawang putih menitikberatkan pendistribusian bawang putih ke beberapa daerah di Indonesia. Tujuan dari penelitian ini adalah untuk mengoptimalkan biaya distribusi yang harus ditanggung oleh Kelompok Tani Sembalun Horti karena biaya distribusi yang ditanggung selama ini sangatlah besar. Karena biaya distribusi antar daerah mempengaruhi pengeluaran biaya distribusi yang harus ditanggung perusahaan. Metode penelitian yang digunakan adalah metode kualitatif dengan menggunakan analisis data model Miles dan Huberman yang dimulai dengan pengumpulan data, mereduksi data, penyajian data dan kesimpulan. penyajian data yang menggunakan metode transportasi yang terdiri dari 3 metode yaitu Northwest Corner, Least Cost, dan Vogel's Approximation Method menghasilkan biaya distribusi yang lebih optimal, khususnya metode Vogel's Approximation Method yang mengoptimalkan biaya distribusi menurun sebesar 13,97\% dari biaya yang harus ditanggung sebelumnya.
\end{abstract}

Kata Kunci: biaya distribusi, optimasi biaya, metode transportasi

\section{Pendahuluan}

Bawang putih adalah herba semusim berumpun yang memiliki tinggi $60 \mathrm{~cm}$. Secara medis, bawang putih memiliki khasiat dalam berbagai hal, diantaranya demam, hipertensi, diabetes, hiperkolesterolemia dan juga penghambat tumbuhnya tumor. Bawang putih memiliki julukan yang berbeda setia daerah contohnya dason putih (Minangkabau), kasuna (Bali), bawang bodas (Sunda), bawang (Jawa Tengah dan Lombok), dan masih banyak lainnya. Bawang putih memiliki umbi berwarna putih yang mempunyai delapan hingga dua puluh siung (anak bawang). Setiap satu siung dengan yang lainnya bawang putih dipisahkan oleh kulit tipis dan liat juga membentuk suatu kesatuan yang rapat serta kuat.

Produksi bawang putih di Indonesia hanya terapat di beberapa daerah saja karena faktor cuaca dan jenis tanah mempengaruhi pertumbuhan tanaman bawang putih. Badan Pusat Statistik dan Direktorat Jendral Hortikultura (2018) berpendapat bahwa produksi bawang putih terdapat pada Provinsi Sumatera Utara, Aceh, Sumatera Barat, Jawa Barat, Jambi, Jawa Timur, Jawa Tengah, Nusa Tenggara Timur, Nusa Tenggara Barat, Bali. Agar bawang putih di Indonesia tersebar 
merata perlu dilakukan pendistribusian keseluruh daerah di Indonesia.

Pendistribusian barang merupakan aktivitas yang mana seorang distributor mengirimikan produknya pada konsumen. Dikarenakan Indonesia merupakan negara kepulauan, pasti terdapat masalah pada aktivitas penyaluran / pendistribusian barang seperti memperkecil anggaran distribusi juga jarak pendistribusian. Oleh karenanya, rute terpendek harus diketahui oleh distributor untuk dapat memperkecil jarak tempuh pendistribusian.
Masalah pendistribusian barang juga disebut masalah Travelling Salesman Problem. Travelling Salesman Problem (TSP) merupakan satu dari beberapa bentuk masalah optimasi yang memiliki tujuan untuk menentukan jalur pendistribusian dimulai dari lokasi semula, mengunjungi lokasi yang dtentukan, hingga kembali ke tempat semula sedemihian rupa sehingga jumlah jarak yang ditempuh sangat kecil juga setiap tempat dikunjungi hanya sekali (Agnes Adventia:2018).

Tabel 1

Komulatif monitoring Penyaluran Benih Bawang Putih (Luar Daerah)

\begin{tabular}{|c|c|c|c|c|c|c|c|c|c|c|c|c|}
\hline \multirow{2}{*}{ Takun } & \multirow{2}{*}{ VARIETAS } & \multirow{2}{*}{$\begin{array}{l}\text { KELAS } \\
\text { BENIH }\end{array}$} & \multicolumn{4}{|c|}{ STOK TARUN INI (TON) } & \multicolumn{5}{|c|}{ PENYALURAN BENH } & \multirow{2}{*}{$\begin{array}{l}\text { Sisa Stok } \\
\text { Thn ini } \\
\text { (GriKglatg) }\end{array}$} \\
\hline & & & $\begin{array}{c}\text { Sisa Stok } \\
\text { Thn Lalu } \\
\text { (Gn:Kg/Btg) }\end{array}$ & $\begin{array}{l}\text { Produksi } \\
\text { Benih } \\
\text { (G:KgBtg) }\end{array}$ & $\begin{array}{l}\text { Pengadaan } \\
\text { dari Luar } \\
\text { Provinsi } \\
\text { (Gekgetg) }\end{array}$ & $\begin{array}{c}\text { Jumiah } \\
\text { (G+Kg Dtgl) }\end{array}$ & $\begin{array}{l}\text { Peryaluran } \\
\text { ke Luar } \\
\text { Provinsi } \\
\text { (GriKg Btg) }\end{array}$ & \multicolumn{2}{|c|}{ Passer Bebas } & Kadaluarse & $\begin{array}{c}\text { Jumlah } \\
\text { (GtKgatg) }\end{array}$ & \\
\hline \multirow{4}{*}{2018} & Sangga Sembalun & $B D$ & 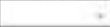 & + & $=$ & . & + & $=$ & 0,005 & 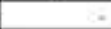 & $=$ & $=$ \\
\hline & & BP & - & - & - & . & - & - & - & - & - & \\
\hline & & $B R$ & - & 1336,418 & . & 1335419 & 15000 & - & 1300308 & . & 1315,358 & 20,050 \\
\hline & & & & & & & & & & & & \\
\hline \multirow{3}{*}{2019} & Senpa Sembalun & BO & - & - & $=$ & - & - & - & - & - & - & \\
\hline & & $B P$ & 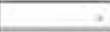 & 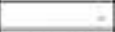 & $=$ & - & $\rightarrow$ & 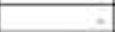 & 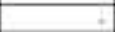 & ?. & $=$ & \\
\hline & & $B R$ & 20000 & 1519,700 & - & 1.135 .750 & 要1900 & 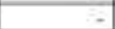 & $=$ & - & 391.400 & 767.850 \\
\hline
\end{tabular}

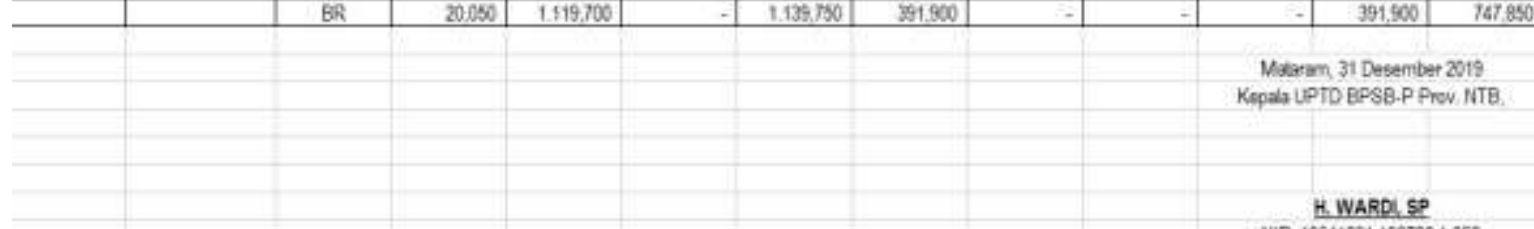

Dari tabel komulatif monitoring penyaluran benih bawang putih diatas dapat dilihat penyaluran benih bawang putih pada tahun 2019 menurun menjadi 391,900Kg. Kepala UPTD BPSB-P Prov. NTB H. Wardi menyatakan bahwa penyaluran benih bawang putih di tahun 2019 menurun akibat biaya distribusi yang besar.

Kelompok Tani Sembalun Horti yang berada di wilayah Lombok Timur, Nusa Tenggara Barat ini ingin meningkatkan pendistribusian bawang putih ke berbagai titik distributor dan menjadi pusat sentra bawang putih di Indonesia. Pengalokasian produk bawang putih juga penentuan rute penyaluran produk dapat menjadi sebuah unsur inti pada perusahaan, karena kelalaian pada penentuan saluran distribusi juga keterlambatan penghantaran produk mampu memperlambat pendistribusian barang dari produsen pada konsumen, sehingga bisa menciptakan kerugian bagi perusahaan. Pada usaha meminimalisi anggaran transportasi penyaluran barang, maka perusahaan wajib mengawasi bagaimana jaringan transportasi yang ada, mulai dari efektivitas, aksesibilitas, kapasistas, tinggi, dan tepat waktu. Guna memproyeksikan permasalahan ini, maka dibutuhkan upaya memberikan biaya pendistribusian yang minimal. Kelompok Tani Sembalun Horti selama ini menggunakan sarana pengiriman melalui pihak ketiga. Karena biaya yang ditafsir sebesar Rp.10.000,-/Kg membuat Kelompok Tani Sembalun Horti ingin menerapkan metode yang baru untuk meminimalkan biaya distribusinya. Sehingga penulis berencana menerapkan metode transportasi riset operasi sebagai metode untuk meminimalkan biaya distribusi.

Berdasarkan beberapa penelitian terdahulu yang diuraikan sebelumnya oleh (Risna, Moch. Aziz, Yusuf Iskandar, Lucky, 2019) berjudul "Optimasi Distribusi dengan Metode Transportasi (Studi Kasus pada Pabrik The X Indah Kabupaten Tasikmalaya)". Hasil analisis penelitian menunjukan bahwa penerapan metode transportasi dapat meminimalisir anggaran distribusi perusahaan sebesar Rp. 5.500.000,-.

Penelitian berikutnya dilakukan oleh (Rizky Kusumawardani, 2017) yang berjudul 
"Optimization of Transportation Cost Using Genetic Algorthm". Hasil penelitiannya menyatakan bahwa kombinasi metode North West Corner dan MODI dalam model Transportasi lebih efektif jika dibandingkan dengan metode algoritma genetika, sebab anggaran transportasi yang ditimbulkan lebih kecil walaupun menggunakan dua tahapan.

Berdasarkan latar belakang yang telah dipaparkan diatas, identifikasi masalah dalam penelitian ini yaitu:

1. Bagaimana menentukan biaya distribusi bawang putih pada Kelompok Tani Sembalun Horti?

2. Bagaimana pengoptimalan biaya distribusi bawang putih dengan menggunakan metode transportasi riset operasi pada Kelompok Tani Sembalun Horti?

\section{Distribusi}

Distribusi adalah suatu kegiatan
ekonomi yang berperan penting sebagai
jembatan yang menghubungkan kegiatan
produksi dengan konsumsi. Barang dan jasa
dapat sampai hingga ke tangan konsumen
karena adanya distribusi barang dan jasa.
Distributor adalah orang yang menjalankan
kegiatan distribusi.

Distribusi adalah salah satu aspek penting dalam sebuah perusahaan, mengingat perannya untuk mengirimkan produk hingga sampai ke tangan konsumen. Pengelolaan distribusi harus benar agar efisien karna akan memberi dampak pada biaya distribusi.

\section{Transportasi}

Menurut Suyadi Prawirosentono (2019) secara umum transportasi berarti adanya perpindahan barang dari sebuah tempat ke tempat lain dan dari beberapa tempat ke beberapa tempat lain. Sumber - sumber (resources) adalah istilah bagi tempat dimana produk tersebut berasal. Sedangkan destination ialah tempat - tempat tujuan. Hal ini ialah bagian dari kehidupan nyata manusia untuk mengalihkan barang dari satu tempat ke tempat lain yang selaras dengan kebutuhan manusia.

\section{Model Transportasi}

Menurut Aminudin (dalam Andini Cipta Permata, dkk 2018) model transportasi ialah gambaran yang diaplikasikan ke dalam model matematika berdasarkan sebuah kasus transportasi, dan dapat membantu berpikir secara cepat dan sistematik tentang kasus tersebut. Bentuk umum Tabel transportasi yakni sebagai berikut:

Tabel 2

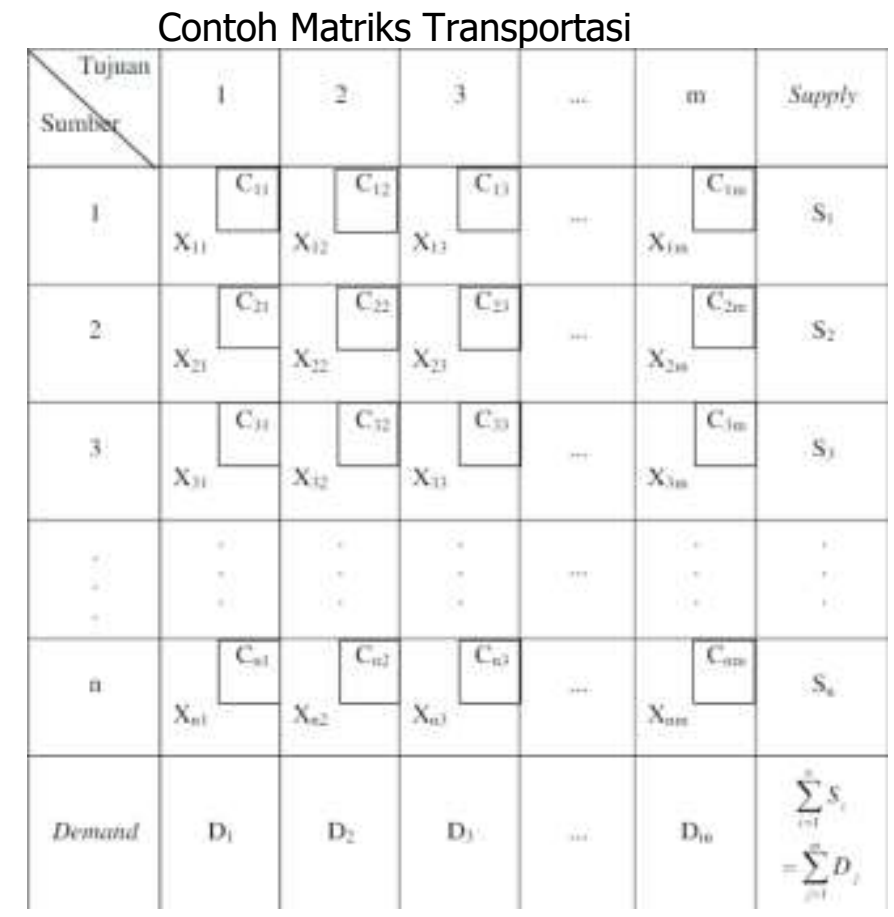


Metode Sudut Barat Laut (North West Corner)

Menurut Aminudin (dalam Andini Cipta Permata, dkk 2018) metode ini dimulai dengan mendistribusikan produk dengan jumlah maksimum yang diperbolehkan oleh penawaran dan permintaan kepada variabel $X_{11}$, sesuai dengan namanya variabel ini berada pada sudut kiri atas atau arah sudut barat laut. Kolom atau baris yang sudah dipenuhi lalu disilang, ini menyatakan bahwa variabel yang berada dalam kolom (baris) yang disilang tersebut ialah sama dengan nol. Hanya satu yang disilang jika sebuah kolom dan baris dipenuhi secara bersamaan. Variabel dasar ditentukan oleh kondisi ini, namun hanya jika ada secara otomatis. Setelah jumlah penawaran dan permintaan disesuaikan dengan semua baris dan kolom yang belum disilang, jumlah maksimum yang layak dialokasikan ke elemen pertama yang belum disilang dikolom (baris) yang baru. Proses ini diselesaikan ketika tepat satu baris (kolom) belum disilang.

\section{Metode Biaya Terendah (Least Cost)}

Menurut Suyadi Prawirosentono (2019)

"Metode biaya terendah (Least Cost) merupakan perbaikan dari steepping stone berbasis Northwest Corner untuk 'menilai' dalam mengisi sel. Jadi, Least Cost adalah cara untuk memulai pengisian sel pada matriks permulaan. Lanjutan penyelesaiannya untuk mencari matriks yang optimum dapat dilakukan dengan stepping stone atau MODI. Jadi, sekali lagi Least Cost model ini cara permulaan mengisi sel pada matriks permulaan"

Tabel 3

Matriks Least Cost

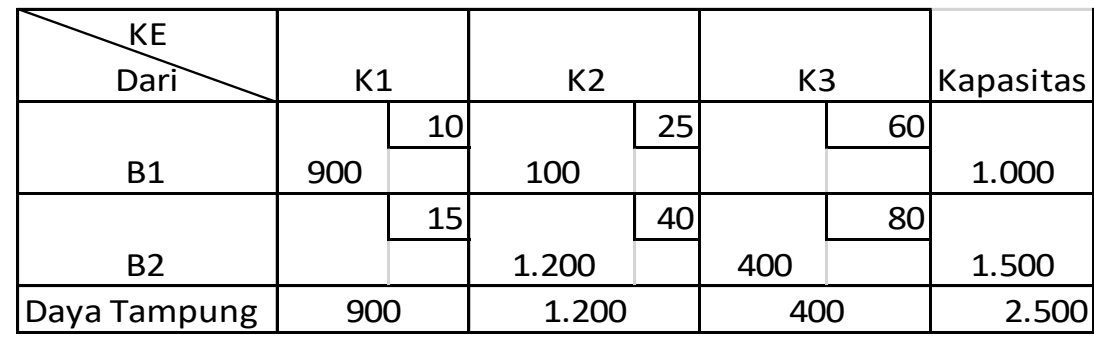

Metode Approksimasi Vogel (Vogel's Approaximation Method) Tabel 4. Matriks VAM

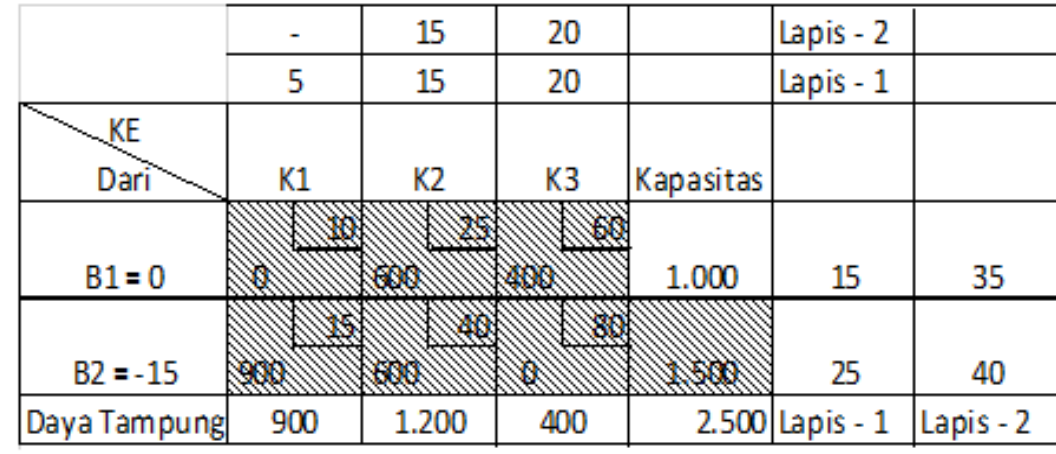

Menurut Suyadi Prawirosentono (2019) metode ini adalah suatu metode heuristic dan pada umumnya menghasilkan pemecahan pertama yang lebih baik dibandingkan metode sebelumnya, yaitu metode North West Corner dan Least Cost. Pada umumnya metode aproksimasi Vogel memberikan hasil pemecahan pertama yang mendekati hasil optimum. Metode VAM terdiri dari:

a. Cari dan hitung selisih angka biaya transport peringkat terkecil dengan angka biaya transport yang lebih besar pada peringkat berikutnya dalam setiap baris dan kolom masing-masing. Contoh peringkat terkecil dengan peringkat berikutnya: dari angka 9, 15, 18, dan 5 . Angka peringkat terkecil 5, sedangkan peringkat berikutnya 9 , jadi selisihnya 9-5 $=4$.

b. Angka selisih dalam butir (a) disimpan di ujung tiap baris atau di ujung puncak kolom masing-masing. 
c. Angka tersebut, yang berada di ujung baris maupun puncak kolom akan dipilih yang selisihnya paling besar. Angka yang dipilih menyatakan baris atau kolom yang sel selnya akan dipilih untuk diisi sesuai dengan daya tamping atau kapasitasnya.

d. Biaya transportasi paling kecil hanya berada pada sel - sel baris atau kolom yang menjadi prioritas untuk mendapatkan alokasi untuk diisi.

e. Sebaiknya baris atau kolom di "arsir" jika baris atau kolom yang selnya diisi telah penuh sebesar kapasitas atau daya tampungnya sebagai "tanda" agar tidak diganggu dalam proses perhitungan selanjutnya. Tetapi, jika baris atau kolom belum penuh karena jumlahnya lebih kecil dari kapasitas maka tidak perlu diarsir.

f. Tahap selanjutnya, menjalani prosedur secara cermat dari (a) sampai dengan (e).

Pada lapisan 1, terdapat perbedaan angka pada kolom dari baris berturut-turut adalah 5, 15, 20, 15, dan 25. Berdasarkan data tersebut, 25 merupakan angka terbesar.

\section{Metode Penelitian}

Penelitian ini menggunakan metode penelitian kualitatif, Sugiyono (2018:9) menuturkan metode penelitian kualitatif yaitu metode penelitian yang berlandaskan pada filsafat positivistime, digunakan untuk meneliti pada kondisi obyek yang alamiah, (sebagai lawannya adalah eksperimen) dimana peneliti sebagai instrumen kunci, teknik pengumpulan data dilakukan secara triangulasi (gabungan), analisis data bersifat induktif / kualitatif dan hasil penelitian kualitatif lebih menekan makna dari pada generalisasi.

Pada penelitian ini penulis memakai sumber data sekunder dan primer. Data primernya berupa struktur organisasi, jalur distribusi, dan kendala perusahaan. Sedangkan data sekundernya berupa data distribusi, tarif dan jumlah muatan.

Teknik analisis yang dipakai pada penlitian ini menggunakan model Miles dan Huberman. Miles dan Huberman (dalam Sugiyono, 2017:246) menjelaskan bahwa kegiatan dalam analisis data kualitatif dilakukan secara interaktif dan dilakukan secara berulang sampai tuntas, hingga data tersebut sudah jenuh.

\section{Hasil Dan Pembahasan}

\section{North West Corner Method}

a. Dari tabel 5 dibawah, kolom di sudut kiri atas diisi terlebih dahulu dengan membandingkan kapasitas supply (310) dan kapasitas demand (250). Dalam hal ini dipilih yang lebih kecil yaitu demand sebesar 250 Ton. Ini berarti kapasitas persediaan sudah diserap oleh demand Jawa Barat, dan gudang Lombok Timur masih memiliki kapasitas pasok sebesar $310-250=60$ Ton.

b. Sisa kapasitas pasok gudang Lombok Timur dialokasikan ke Jawa Tengah 60 Ton agar dapat memenuhi demand dan mengkosongkan supply gudang Lombok Timur dimana sudah teralokasikan ke demand Jawa Barat dan Jawa Tengah.

c. Kemudian pengalokasian dilakukan dari gudang Lombok Utara ke Jawa Tengah karena demand Jawa Tengah masih belum terpenuhi sebanyak 240 Ton.

d. Sisa supply gudang Lombok Utara sebanyak 10 Ton, maka pengalokasian dilakukan dari gudang Lombok utara ke Sulawesi sebanyak 10 Ton. Maka supply gudang Lombok Utara teralokasikan ke demand Jawa Tengah dan Sulawesi.

e. Karena sisa demand Sulawesi dan supply

Lombok Barat sebanyak 190 Ton, maka sisa demand Sulawesi langsung teralokasikan dari supply Lombok barat sebanyak 190 Ton.

Tabel 5

Iterasi North West Corner

\begin{tabular}{|c|c|c|c|c|c|c|c|}
\hline $\mathrm{Ke}$ & Jaw & Barat & Jaw & engah & & Nesi & Supply \\
\hline $\begin{array}{c}\text { Lombok } \\
\text { Timur }\end{array}$ & $\begin{array}{c}\text { a. } \\
250\end{array}$ & 2000 & $\begin{array}{l}\text { b. } \\
60\end{array}$ & 1600 & $X$ & 1000 & 310 \\
\hline Lombok & $X$ & 1800 & C. & 1200 & d. & 1300 & 250 \\
\hline
\end{tabular}




\begin{tabular}{|c|c|c|c|c|c|c|c|}
\hline Utara & & & 240 & & 10 & & \\
\hline $\begin{array}{c}\text { Lombok } \\
\text { Barat }\end{array}$ & $X$ & 1500 & $X$ & 1100 & 190 & 1150 & 190 \\
\hline Demand & & 50 & & 300 & & 200 & 750 \\
\hline
\end{tabular}

Total biaya Transportasi $=(250 \times 2000)+(60 \times 1600)+(240 \times 1200)+(10 \times 1300)+$ $(190 \times 1150)=1.115 .500 \times \operatorname{Rp} 1.000=\operatorname{Rp} 1.115 .500 .000$

\section{Metode Least Cost}

a. Dari tabel 6 dibawah gudang Lombok Timur-Sulawesi adalah variabel yang memiliki biaya unit terkecil yaitu 1.000 . Karena demand ke Sulawesi sebanyak 200 Ton dan supply gudang Lombok Timur sebanyak 310, maka akan dialokasikan supply dari gudang Lombok Timur ke Sulawesi sebanyak 200 Ton. Demand ke Sulawesi sudah terpenuhi.

b. Gudang Lombok Barat-Jawa Tengah adalah varibel yang memiliki biaya unit terendah selanjutnya yaitu 1.100 . karena demand Jawa Tengah sebanyak 300 Ton dan supply gudang Lombok Barat 190 Ton, maka supply gudang Lombok Barat akan dialokasikan ke Jawa Tengah sebanyak 190 Ton. Supply gudang Lombok Barat sudah terpenuhi.

c. Gudang Lombok Utara-Jawa Tengah adalah variabel yang memiliki biaya unit terendah selanjutnya yaitu 1.200. karena sisa demand Jawa Tengah sebanyak 110 Ton (300-190) dan supply Lombok Utara 250 Ton, maka supply Lombok Utara dialokasikan ke Jawa Tengah sebanyak 110 Ton. Demand Jawa Tengah sudah terpenuhi.

d. Gudang Lombok Utara-Jawa Barat adalah variabel terakhir yang memiliki nilai unit terendah yaitu 1800. Karena sisa supply gudang Lombok Utara sebanyak 140 Ton dan demand Jawa Barat 250 Ton, maka sisa supply gudang Lombok Utara dialokasikan untuk Jawa Barat sebanyak 140 Ton. Supply gudang Lombok Utara sudah terpenuhi.

e. Karena sisa demand Jawa Barat dan supply gudang Lombok Timur sebanyak 110 Ton maka sisa demand Jawa Barat dialokasikan langsung dari supply gudang Lombok Timur untuk saling memenuhi.

Tabel 6

Iterasi Least Cost

\begin{tabular}{|c|c|c|c|c|c|c|c|}
\hline Ke & \multicolumn{2}{|c|}{$\begin{array}{l}\text { Jawa } \\
\text { Barat }\end{array}$} & \multicolumn{2}{|c|}{$\begin{array}{c}\text { Jawa } \\
\text { Tengah }\end{array}$} & \multicolumn{2}{|c|}{ Sulawesi } & Supply \\
\hline $\begin{array}{c}\text { Lombok } \\
\text { Timur }\end{array}$ & $\begin{array}{c}\text { e. } \\
110\end{array}$ & 2000 & $X$ & 1600 & $\begin{array}{c}\text { a. } \\
200\end{array}$ & 1000 & 310 \\
\hline $\begin{array}{c}\text { Lombok } \\
\text { Utara }\end{array}$ & $\begin{array}{c}d . \\
140 \\
\end{array}$ & 1800 & $\begin{array}{c}\mathrm{C} . \\
110\end{array}$ & 1200 & $X$ & 1300 & 250 \\
\hline $\begin{array}{c}\text { Lombok } \\
\text { Barat }\end{array}$ & $x$ & 1500 & $\begin{array}{l}\text { b. } \\
190\end{array}$ & 1100 & $X$ & 1150 & 190 \\
\hline Demand & \multicolumn{2}{|c|}{250} & \multicolumn{2}{|c|}{300} & \multicolumn{2}{|c|}{200} & 750 \\
\hline
\end{tabular}

Total biaya transportasi $=(110 \times 2000)+(200 \times 1000)+(140 \times 1800)+(110 \times 1200)+$ $(190 \times 1100)=1.013 .100 \times \operatorname{Rp} 1.000=\operatorname{Rp} 1.013 .100 .000$

\section{Vogel's Approaximation Method}

a. Dari tabel 7 dibawah harus menghitung selisih antara variabel terendah dari masing-masing tujuan. Jawa Barat memiliki variabel terendah 1800 dan 1500 maka selisihnya 300, Jawa Tengah memiliki variabel terendah 1200 dan 1100 maka selisihnya 100, Sulawesi memiliki variabel terendah 1150 dan 1000 maka selisihnya 150. Gudang Lombok Timur memiliki variabel terendah 1600 dan 1000 maka 
selisihnya 600, gudang Lombok Utara memiliki variabel terendah 1300 dan 1200 maka selisihnya 100, dan gudang Lombok Barat memiliki variabel terendah 1150 dan 1100 maka selisihnya 50.

b. Selisih terbesar pada baris a. yaitu 600, alokasikan sebanyak mungkin pada variabel sel yang memiliki biaya terendah yaitu Sulawesi 1000 sebanyak 200 Ton, maka terpenuhi demand Sulawesi sebanyak 200 Ton.

c. Kemudian pengalokasian menurut selisih terbesar pada kolom a. Yaitu 300, maka pengalokasiannya dari gudang Lombok Barat ke Jawa Barat sebanyak 190 Ton. Supply gudang Lombok Barat terpenuhi.

d. Setelah itu menghitung selisih dari sisa variabel unit terbesar berdasarkan gudang. Gudang Lombok Timur memiliki sisa variabel yaitu 2000 dan 1600 maka selisihnya 400, gudang Lombok Utara memiliki sisa variabel yaitu 1800 dan 1200 maka selisihnya 600 . Jawa barat memiliki sisa variabel yaitu 2000 dan 1800 maka selisihnya 200, Jawa Tengah memiliki sisa variabel yaitu 1600 dan 1200 maka selisihnya 400.

e. Selisih terbesar pada poin d. diatas yaitu 600, maka akan dilakukan pengalokasian terbanyak dari gudang Lombok Utara ke Jawa Tengah sebanyak 250 Ton, maka supply gudang Lombok Utara terpenuhi.

f. Selanjutnya karena sisa supply gudang Lombok Timur sebanyak 60 Ton dan demand Jawa Barat sebanyak 60 Ton maka akan di alokasikan untuk Lombok TimurJawa Barat sebanyak 60 Ton

Tabel 7

Iterasi Vogel's Approaximation Method

\begin{tabular}{|c|c|c|c|c|c|c|c|c|c|}
\hline $\begin{array}{c}\text { Selisih terbesar } \\
\text { selanjutnya yaitu } \\
400, \text { maka } \\
\text { pengalokasian } \\
\text { dilakukan ke Jawa } \\
\text { Tengah dari } \\
\text { gudang Lombok } \\
\text { Timur untuk } \\
\text { memenuhi } \\
\text { demand Jawa } \\
\text { Tengah sebanyak } \\
50 \text { TonKe } \\
\text { Dari }\end{array}$ & \multicolumn{2}{|c|}{ Jawa Barat } & \multicolumn{2}{|c|}{ Jawa Tengah } & \multicolumn{2}{|c|}{ Sulawesi } & \multirow[t]{2}{*}{$\begin{array}{r}\text { Supply } \\
\\
310\end{array}$} & \multirow[t]{2}{*}{$\begin{array}{l}\text { a. } \\
600\end{array}$} & \multirow[t]{2}{*}{$\begin{array}{l}\text { d. } \\
400\end{array}$} \\
\hline Lombok Timur & g. 60 & 2000 & f. 50 & 1600 & b. 200 & 1000 & & & \\
\hline Lombok Utara & $x$ & 1800 & e. 250 & 1200 & $x$ & 1300 & 250 & 100 & 600 \\
\hline Lombok Barat & C. 190 & 1500 & $x$ & 1100 & $x$ & 1150 & 190 & 50 & \\
\hline Demand & & & & & & & 750 & & \\
\hline a. & & & & & & & & & \\
\hline d. & & & & & & & & & \\
\hline
\end{tabular}

Total biaya transportasi $=(60 \times 2000)+(50 \times 1600)+(200 \times 1000)+(250 \times 1200)+(190 \times 1500)$ $=985.000 \times \operatorname{Rp} 1.000=\operatorname{Rp} 985.000 .000$

\section{Mengambil Keputusan}

Dari penyajian data pengoptimalan biaya distribusi bawang putih diatas yang menggunakan metode Northwest Corner, Least Cost, dan Vogel's Approximation Method 
memiliki hasil perhitungan yang berbeda antara lain:

1. Metode Northwest Corner dengan hasil akhir sebesar Rp 1. 115.500.000,-

2. Metode Least Cost dengan hasil akhir sebesar Rp 1.013.000.000,-

3. Metode Vogel's Approximation Method dengan hasil akhir sebesar Rp 985.000.000,-

Dari ketiga metode tersebut hasil yang paling optimal adalah metode Vogel's Approximation Method dengan hasi akhir sebesar Rp 985.000.000,-. Dan untuk mereduksi biaya yang tak terduga akibat kerusakan bawang putih Kelompok Tani Sembalun Horti mengasuransikan pengiriman bawang putih tersebut dengan total biaya Rp. 15.000.000,- Jadi total biaya transportasi yang harus dikeluarkan Kelompok Tani sebesar Rp. 1.000.000.000,- . Biaya transportasi yang ada sebelum perhitungan adalah $\mathrm{Rp}$ 1.162.500.000,- jadi terdapat penurunan ongkos $13,97 \%$

\section{Analisis Data Metode Transportasi}

Dari hasil pengolahan data dengan menggunakan aplikasi Microsoft Office Excel 2016, maka didapat hasil perhitungan persoalan transportasi menggunakan metode Vogel's Approximation Method dan Stepping Stone Methode. VAM merupakan sebuah metode heuristic yang memberikan pemecahan awal yang lebih baik daripada metode sebelumnya, yaitu Northwest Corner dan Least cost Method. Pada kenyatanyaan VAM memberikan sebuah pemecahan awal yang mendekati hasil optimum. Juga studi literatur yang dilakukan adalah perhitungan persoalan transportasi dengan menggunakan metode VAM dan Stepping Stone. Hasil perhitungan dapat dilihat seperti Gambar 4. dan analisisnya sebagai berikut. Jumlah kapasitas pendistribusian barang dari Gudang Lombok Timur ke Jawa Barat sebanyak 60 ton, dari Gudang Lombok Timur ke Jawa Tengah sebanyak 50 ton, dari Gudang Lombok Timur ke Sulawesi sebanyak 200 ton, dari Gudang Lombok Utara ke Jawa Tengah 250 ton dan dari Gudang Lombok Barat ke Jawa Barat sebanyak 190 ton. Dengan perhitungan persoalan transportasi pengoptimalan ongkos pengiriman barang agar perusahaan memperoleh keuntungan yang lebih besar yaitu dari Gudang Lombok timur ke Jawa Barat sebanyak 60 ton dengan biaya pengiriman per ton sebesar Rp 2.000.000,- dan ongkos pengiriman sebesar Rp 120.000.000,-, dari Gudang Lombok Timur ke Jawa Tengah sebanyak 50 ton dengan biaya pengiriman per ton sebesar Rp 1.600.000,- dan ongkos pengiriman sebesar Rp 80.000.000,-, dari Gudang Lombok Timur ke Sulawesi sebanyak 200 ton dengan biaya pengiriman per ton sebesar Rp 1.000.000,- dan ongkos pengiriman sebesar Rp 200.000.000,-, dari Gudang Lombok Utara ke Jawa Tengah sebanyak 250 ton dengan biaya pengiriman per kilogram sebesar Rp 1.200.000,-, dan ongkos pengiriman sebesar Rp 300.000.000,-.dan dari Gudang Lombok Barat ke Jawa Barat sebanyak 190 ton dengan biaya pengiriman per kilogram sebesar Rp 1.500.000,- dan ongkos pengiriman sebesar $\mathrm{Rp}$ 285.000.000,--. Biaya total pendistribusian bawang putih adalah sebesar Rp 985.000.000,-

\section{Kesimpulan}

Kesimpulan yang diperoleh dari penelitian ini ialah dengan perhitungan metode transportasi riset operasi yang menggunakan perhitungan manual dan menggunakan aplikasi POM QM dan aplikasi Microsoft Excel. Dengan hasil perhitungan 3 metode yang terdapat pada metode transportasi riset operasi yaitu Northwest Corner,Least Cost, dan Vogel's Approximation Method maka dihasilkan jumlah kapasistas pendistribusian barang dan pengoptimalan ongkos pengiriman barang agar Kelompok Tani Sembalun Horti mendapatkan keuntungan yang lebih besar jika menggunakan metode Vogel's Approximation Method dan Iterasi diantara Northwest Corner dan Least Cost. Untuk penelitian yang lebih baik kedepannya penulis menyarankan agar penelitian yang serupa dengan ini dilakukan dengan mengolah data lebih banyak lagi agar nantinya akan mendapatkan solusi yang lebih optimum pada penentuan biaya yang dicari.

\section{Daftar Pustaka}

Adventia, Khusnul Novianingsih, Husty Serviana. 2018. Penyelesaian Masalah Pendistribusian Barang Menggunakan Algoritma Bee Colony Optimization. Universitas Pendidikan Indonesia 
Dewi, Haikal Arsyan, Pande Gede Rama. 2018.

Optimasi Ongkos Minimum

Pendistribusian Barang Pewarna Tekstil Pada Perusahaan RPX. Sekolah Tinggi Ilmu Logistik Indonesia.

Kartika, Moch. Aziz, Yusuf Iskandar, Lucky Adhitia. 2019. Optimasi Distribusi Dengan Metode Transportasi (Studi Kasus pada Pabrik Teh $X$ Indah Kabupaten Tasikmalaya. Universitas Galuh.

Kusumawardani Rizky. 2017. Optimization of Transportation Cost Using Genetic Algorthm. Universitas Islam Indonesia Yogyakarta.

Prawirosentono, S. (2019). Riset Operasi \& Ekonofisika (Operations Research \& Econophysics) Edisi Revisi. Jakarta: Bumi Aksara.

Sugiyono. (2017). Metode Penelitian Kuantitatif, Kualitatif dan R\&D. Bandung: Alfabeta.

Sugiyono. (2018). Metode Penelitian Kuantitatif, Kualitatif dan R\&D. Bandung: Alfabeta. 